\section{AUTHOR'S RESPONSE 1}

\section{doi $10.1308 / 003588407 \times 155617$}

\section{ROBERT WHEELER}

Child Health Directorate, Wessex Regional Centre for Paediatric Surgery, Southampton General Hospital, Southampton, UK

\section{CORRESPONDENCE TO}

Robert Wheeler, Consultant Paediatric and Neonatal Surgeon, Child Health Directorate, Wessex Regional Centre for Paediatric Surgery, G Level, East Wing, Mailpoint 44, Southampton General Hospital, Tremona Road, Southampton S016 6YD, UK

E: robert.wheeler@suht.swest.nhs.uk

The comments by Hamilton and colleagues are timely. Since the legal rules governing surgical practice are as pertinent as the physiological and pathological rules which we derive from basic sciences, there is a powerful argument for ensuring that all surgeons, at whatever level, have adequate formal training in the current law.

If difficulty is encountered, a surgeon should seek advice, and the local Clinical Ethics Committee may be an appropriate source.

The patient safety alert to which Hamilton and colleagues refer gives a rather low standard when applied to matters of consent. This is because there is no requirement that the nominated deputy should be capable of performing the procedure in question. Therefore, under such a standard, it would be possible that a patient's consent would be obtained by an individual who is ill-equipped to provide it.

It is accepted that the survey may indicate woeful ignorance amongst surgeons when it comes to the issue of consent. Nevertheless, this survey needs to be taken with some caution. Psychiatric patients may be perfectly competent to provide consent providing that their psychiatric state has no bearing on the decision of whether surgery is appropriate. In the case of Re C [1994] 1 All ER 819, a schizophrenic Broadmoore patient was held to be entitled to refuse to have his leg amputated. This man had an illness which caused him to believe (erroneously) that he was a world-famous surgeon; however, the court found that he understood the nature and purpose of amputation and realised that he might die of the underlying gangrene if he refused treatment. It is salutary to note that the amputation proved unnecessary and his infection was successfully treated with antibiotics.

\section{COMMENT 2}

\section{doi 10.1308/003588407X155626}

\section{Consent}

Y FONG, P LEWIS, MH LEWIS

Department of Surgery, Royal Glamorgan Hospital, Llantrisant, UK

\section{CORRESPONDENCE TO}

MH Lewis, Consultant Surgeon, Department of Surgery, Royal Glamorgan Hospital, Ynysmaerdy, Llantrisant, Rhondda Cynon Taf CF72 8XR, UK

E: caron.potter@pr-tr.wales.nhs.uk

In the climate of a flourishing medicolegal industry, where all aspect of clinical practice can, and will, be scrutinised with a fine-toothed legal comb, the burden of proof and responsibility often fall upon the medical profession which places a financial penalty on the health service. We feel that the emphasis of obtaining consent has now shifted to producing legal defence papers rather than providing information and understanding of a procedure to the patient.

One of us was recently involved with a bungee jumping event abroad. The consent for this is for an event with no intention of improving the quality of life but, in fact, puts life at risk. If the NHS employed a similar 'consent' framework, it would read like the following:

1. I accept that surgery carries with it some degree of risk, both to person and property, and of emotional trauma of friends and family. Knowing the risk I still wish to participate in surgery and so expressly agree to assume the risk.

2. I release, waive and hold harmless the NHS Trust, its officers and/or its employees from all claims, losses, damages or expenses including legal costs that may be incurred during or in conjunction with my participation in surgery.

3. I also indemnify the NHS Trust, its officers and/or its employees against all claims, losses, damages or expenses including legal costs that any of my family or their executors, administrators, heirs, next of kin, successors or assignees may have or assert against the NHS Trust as a result of my participation in surgery.

4. I hereby consent to receive further treatment deemed to be necessary by the NHS Trust in the case of injury, accident or illness during the course of surgery and also agree to indemnify the NHS Trust in respect of such treatment.

It is made clear from the consent form for the voluntary act of jumping off a bridge for momentary exhilaration, that the participant has to assume all risks. An assumption is made that all safety procedures have been followed and all 